\title{
EL CONTENIDO DEL DERECHO A UN PROCESO CON TODAS LAS GARANTÍAS EN LA SEGUNDA INSTANCIA PENAL A LA LUZ DE LA JURISPRUDENCIA DEL TEDH
}

\author{
NICOLÁS PÉREZ SOLA \\ Catedrático de Derecho Constitucional \\ Universidad de Jaén
}

\section{SUMARIO}

I. Introducción. II. Ámbito de aplicación del CEDH. III. El contexto interno. IV. El principio de inmediación. V. Los pronunciamientos del TEDH condenatorios al Estado español. VI. La recepción por el TC de la jurisprudencia del TEDH.

\section{INTRODUCCIÓN}

Aunque es cierto, como se ha señalado desde la doctrina ${ }^{1}$, que ha existido en la jurisprudencia constitucional una cierta indeterminación a la hora de ubicar el derecho al doble grado de jurisdicción en nuestra Norma Fundamental, ya que en ocasiones parecía encontrar su espacio en el derecho al proceso con todas las garantías (art. 24.2 CE) y, más tarde, en el más genérico derecho a la tutela judicial efectiva, su interpretación a la luz del art. 6 del Convenio Europeo de Derechos Humanos (en adelante CEDH) resulta imprescindible. Pero más allá de contrastar la adecuación de nuestro sistema de recursos en el ámbito penal a la jurisprudencia del Tribunal Europeo de Derechos Humanos (en adelante TEDH), es evidente que la casuística que presentan las garantías dimanantes del art. $6 \mathrm{CEDH}$ a la luz de la jurisprudencia de aquél, excede con mucho los intentos por parte de nuestro alto Tribunal de adecuar su doctrina a dichos pronunciamientos interpretativos de las garantías en la segunda instancia penal derivadas del citado precepto del Convenio.

Las repercusiones que se derivan para la jurisprudencia del TC en materia de garantías en segunda instancia penal transcienden en efecto de las concretas sentencias de

1 SÁrz ArNárz, A., «El derecho fundamental al recurso en el orden penal y la interpretación del art. 24.1 de la CE de conformidad con el Derecho internacional y europeo de los Derechos Humanos (especial referencia a la situación de los aforados y a los supuestos de conexidad)», REDE, n. ${ }^{\circ}$ 5, 2003, p. 79. 
condena al Estado español que serán objeto de consideración posterior, por lo que pretendemos analizar si el giro jurisprudencial operado por nuestro Tribunal de garantías constitucionales muestra una acertada y completa recepción por éste de la jurisprudencia del Tribunal Europeo, tras la reforma procesal penal en nuestro país aprobada en 2015. Para ello, nos hemos de ocupar del impulso que la jurisprudencia constitucional ha propiciado del principio de inmediación y su cumplimiento por el órgano ad quem, con especial interés en la casuística que presenta la doble instancia penal cuando la primera de las sentencias resulta absolutoria y cómo opera entonces el derecho al recurso, la valoración de la prueba, la contradicción entre las partes y la inmediación, que además ha sido objeto de reflexión doctrinal como de consideración por nuestros tribunales ${ }^{2}$.

Hemos de partir de un sistema de recursos previamente establecido en el ordenamiento interno en el que no está generalizada la segunda instancia a través del recurso de apelación y la casación, sino que queda circunscrita a supuestos tasados. No obstante, estas previsiones legales deben ser contrastadas con las exigencias convencionales en la materia para determinar su adecuación a las derivadas de nuestras obligaciones internacionales y, especialmente, del CEDH. Los interrogantes que quedan planteados a la luz de la jurisprudencia de Estrasburgo son diversos y no admiten una única respuesta. En un primer momento deberíamos cuestionarnos los términos en que debe desarrollarse la segunda instancia. En efecto, el dilema entre si debe contener una revisión completa de lo actuado en primera instancia o debe estar limitada, persiste en la actualidad.

Además, la eventualidad de la segunda instancia condenatoria tras la primera instancia absolutoria, nos llevará a interrogarnos sobre si ¿Es constitucionalmente necesaria la previsión de una nueva instancia de revisión tras el pronunciamiento condenatorio en segunda instancia en el proceso penal?.

A partir de aquí, cabría cuestionarse si ¿Alcanza la exigencia de inmediación a la práctica de todas las pruebas en segunda instancia? o ¿Tan solo a aquellas de carácter personal (audiencia pública, testigos y peritos)? Incluso puede surgir la duda respecto de ¿Hasta dónde llegan las exigencias del proceso contradictorio?

Vemos como son diversos los interrogantes que deben ser analizados a tenor de los compromisos internacionales contraídos por el Estado español ${ }^{3} \mathrm{y}$, puesto que contamos con pronunciamientos de las instancias internacionales, como de nuestros órganos de constitucionalidad y jurisdiccionales, la búsqueda de respuestas a través de su estudio puede resultar más fácil para determinar en qué medida, las consecuencias de aquéllos han sido incorporadas a nuestro ordenamiento.

Sirva como punto de partida la constatación de que es en esta materia en la que se evidencia una notoria falta de sintonía entre el sistema del CEDH y nuestro ordenamiento procesal penal, significativamente en relación con el derecho al proceso. Recordemos que nuestro

2 Hay que recordar que el propio TC se había manifestado sobre la posición que le correspondía en este contexto indicando que «no es misión de este Tribunal proponer una regulación constitucionalmente óptima de los recursos en el procedimiento penal ni valorar la vigente en términos de mayor o menor adecuación a los valores constitucionales, sino simplemente determinar si el recurso invocado por los recurrentes constituye una garantía exigida por el art. 24.2 CE» (STC 296/2005).

3 «La remisión que el art. 10.2 CE hace a la DUDH y a los Tratados y Acuerdos Internacionales sobre las mismas materias suscritos por España para la interpretación de las normas constitucionales sobre derechos fundamentales y libertades públicas, autoriza y aun aconseja referirse para la búsqueda de estos criterios, a la doctrina sentada por el TEDH al aplicar la norma contenida en el art. 6.1 del Convenio» (STC 36/1984). 
alto Tribunal ha reiterado que «el derecho a la segunda instancia en el orden penal (...) es producto de la conexión de los artículos 24.1 y $10.2 \mathrm{CE}{ }^{4}$. Bien es cierto que más allá de la jurisprudencia emanada del Tribunal de Estrasburgo en relación al artículo 6 del CEDH, es en el art. 2 del Protocolo 7 del Convenio donde se recoge expresamente este derecho ${ }^{5}$, dicho Protocolo sólo ha sido ratificado por España en fecha relativamente reciente, habiendo entrado en vigor en 2009. Puede estar quizá en la tardía ratificación del citado Protocolo una de las razones por las que las quejas contra el Estado español, en orden a la vulneración del derecho a la doble instancia penal, se han presentado ante el Comité de Derechos Humanos de Naciones Unidas, aunque ambos instrumentos de protección de derechos Pacto Internacional de los Derechos Civiles y Políticos (en adelante PIDCP) y CEDH están disponibles para su invocación frente a hipotéticas vulneraciones de los mismos por los Estados Parte ${ }^{6}$.

\section{II. ÁMBITO DE APLICACIÓN DEL CEDH}

Como es notorio, la redacción más precisa del apartado 2 del artículo 1 del Protocolo 7 del CEDH y su ratificación por el Estado español permite incorporar al análisis que en estas páginas se realiza, de este precepto en conexión con el art. 6 del citado texto internacional, si bien, por razones temporales, los casos enjuiciados por el TEDH contra el Reino de España, lo han sido por la presunta vulneración de éste último precepto, ya que aún antes de su ratificación por el Estado español ya había sido invocado desde el alto Tribunal, algo que ha resultado paradójico y no ha escapado a la consideración de la doctrina. Pero antes de avanzar en este análisis debemos dejar constancia de los ámbitos que pueden resultar potencialmente contrarios a la jurisprudencia del Tribunal de Estrasburgo, en la medida en que nuestro ordenamiento prevé diversos supuestos en los que la doble jurisdicción no está garantizada y, sobre los que hasta el momento no ha habido pronunciamiento del Tribunal Europeo.

Nos referimos esencialmente a los supuestos de única instancia en los casos de los aforados así como a la privación de una segunda instancia en aquellos otros supuestos en los que los afectados se ven arrastrados por su conexión con aforados a la única instancia del TS. En efecto, por cuanto se refiere a los aforados no cabe extraer una conclusión en términos absolutos sobre su encaje constitucional. Ciertamente el artículo 71.3 CE no permite una respuesta contundente. Es cierto que la jurisprudencia constitucional no ha cuestionado en un juicio de ponderación la adecuación a nuestra Norma Fundamental de una instancia única para juzgar a Diputados y Senadores ${ }^{7}$ pero, no por ello, cabe discrepar

4 «El Tribunal Constitucional ha llevado a cabo una labor de identificación de los contenidos constitucionalmente declarados del derecho a la tutela judicial efectiva que le venía impuesta por la interpretación internacionalmente adecuada de los derechos fundamentales que resulta del art. 10.2 CE». SÁrz ArNárz, A., «El derecho fundamental al recurso en el orden penal...» Op. Cit., p. 76.

5 «Toda persona declarada culpable de una infracción penal por un Tribunal tendrá derecho a que la declaración de culpabilidad o la condena sea examinada por una jurisdicción superior. El ejercicio de ese derecho, incluidos los motivos por los cuales pueda ser ejercitado, se regularán por ley».

6 Nos hemos ocupado de la interpretación llevada a cabo por el TC del art. 14.5 PIDCP en PÉrEz SOLA, N., La defensa convencional de los derechos en España. ¿Es posible el diálogo entre tribunales?, INAP, Madrid 2015.

7 «Ha de entenderse que el constituyente efectuó una inicial ponderación del derecho al doble grado de jurisdicción de Diputados y Senadores y de las necesidades de protección, tanto de la independencia de la propia institución parlamentaria como del Poder judicial» (STC 64/2001). 
de tal conclusión ${ }^{8}$. Insistiendo más en este argumento, como ha señalado la doctrina, no cabe deducir sin mayor cuestionamiento, la excepcionalidad de la única instancia penal en las causas en las que estén implicados aforados y, por ello, con más razón quienes quedasen arrastrados a la jurisdicción única del TS sin ser aforados «por razón de conexidad» ${ }^{9}$. Además hemos de recordar como con ocasión del voto particular a la STC $37 / 1988^{10}$ fue propuesta la generalización de la apelación. Pese a la posición de nuestro alto Tribunal al respecto (entre otras SSTC 64, 65 y 66/2001), desde la doctrina se ha mantenido la imposibilidad de que se prive del derecho a la doble jurisdicción a cualquier categoría de personas ${ }^{11}$ y no sólo los aforados sino a aquellos que se ven arrastrados por razones de conexidad.

Corresponde ahora centrarnos en los casos en los que el Tribunal de Estrasburgo ha apreciado la vulneración del art. $6 \mathrm{CEDH}$ en el ámbito de procedimientos penales, si bien se debe destacar que la consideración por el Tribunal Europeo del sentido y alcance del art. 2, del Protocolo núm. 7 del $\mathrm{CEDH}^{12}$ ha experimentado también una evolución que debe ser tenida en cuenta al objeto de una mejor comprensión de su doctrina.

En efecto, existen claros pronunciamientos del TEDH respecto de la no vulneración del CEDH por la inadmisibilidad del recurso de casación ${ }^{13}$, no obstante también el Tribunal de Estrasburgo ha afirmado que «las limitaciones impuestas por las legislaciones internas al derecho al recurso (....) deben, por analogía con el derecho de acceso al tribunal (...) perseguir un fin legítimo y no atentar contra la sustancia misma de este derecho» ${ }^{14}$. Por ello y de modo sucinto recordamos un conjunto de pronunciamientos de este Tribunal que han completado la interpretación del art. 6 del CEDH que tendrán que ser atendidos, sin perjuicio de las características de cada proceso, dentro del conjunto del ordenamiento interno de cada Estado parte.

En la resolución del Caso Delcourt contra Bélgica ${ }^{15}$, el Tribunal Europeo señaló que el art. 6 del CEDH no contiene una obligación para los Estados de crear tribunales de apelación o casación, ahora bien, cuando disponga de ellos, está obligado a asegurar que los justiciables gocen ante los mismos de las garantías fundamentales del citado precepto. Un paso más adelante en esta evolución puede ejemplificarse con la resolución de

8 El voto particular del Magistrado Vives Antón cuestiona el parecer mayoritario del Tribunal, ya que si la interpretación que se realiza por el TC con carácter mayoritario sobre el citado art. $71.3 \mathrm{CE}$ constituye una excepción al derecho al doble grado de jurisdicción, «sería necesario que el precepto lo dispusiera expresamente o, al menos, que ese carácter de excepción pudiera inferirse implícitamente de la incompatibilidad entre la garantía y el precepto constitucional que impone el aforamiento».

9 SÁrz Arnárz, A., «El derecho fundamental al recurso en el orden penal....». Op. Cit., p. 85.

10 Voto particular formulado por el Magistrado Vega Benayas al que se adhieren los Magistrados García-Mon, Díaz Eimil y Rubio Llorente.

11 «En el caso de quienes resultan afectados por conexión el arrastre supone para quien lo sufre la privación de su derecho a someter la declaración de culpabilidad y la pena ante un Tribunal superior, y ello en ausencia de todo fuero procesal». SAIz ArnaIz, A., «El derecho fundamental al recurso en el orden penal...». Op. Cit, p. 85.

12 «Toda persona declarada culpable de un delito tendrá derecho a que el fallo condenatorio y la pena que se le haya impuesto sean sometidos a un Tribunal superior, conforme a lo prescrito por la ley. 2. Este derecho podrá ser objeto de excepciones en el caso de infracciones de menor gravedad, según las define la ley, o cuando el interesado haya sido juzgado en primera instancia por el más alto tribunal o haya sido declarado culpable y condenado al resolverse un recurso contra su absolución».

13 Caso Papon contra Francia, STEDH de 25 de julio de 2002.

14 Caso Krombach contra Francia, STEDH de 13 de febrero de 2011.

15 STEDH de 17 de enero de 1970. 
los Casos Pakelli contra República Federal de Alemania ${ }^{16}$ y Axen contra República Federal de Alemania, así como en el Caso Sutter contra Suiza, todas ellas relativas a la publicidad de los debates. Esta línea jurisprudencial se completa con la resolución del Caso Colozza contra Italia ${ }^{17}$ que incorpora a la noción de juicio justo la presencia del acusado en los debates del proceso.

Un gran eco tuvo en la doctrina del TC la sentencia del Caso Ekbatani contra Sue$\mathrm{cia}^{18}$, en la que el Tribunal de Estrasburgo indica que «en las circunstancias de la causa, ésta no podía resolverse de modo adecuado, a los fines del proceso justo, sin una apreciación directa de los testimonios personales del recurrente - que alegaba no haber cometido el hecho- y del denunciante, por lo que el nuevo examen por el tribunal de apelación de la declaración de culpabilidad que discutía el Sr. Ekbatani hubiera debido exigir una nueva audiencia íntegra de los dos interesados», ya que el único material probatorio descansaba en las declaraciones del denunciante frente al acusado que tan solo había reclamado al TEDH ser oído en audiencia pública. En suma en este conjunto de sentencias y en otras posteriores se lleva a cabo un análisis casuístico para determinar por el Tribunal de Estrasburgo si atendiendo al procedimiento interno en su conjunto, como a las características del recurso de apelación concreto, debiera haberse celebrado en la fase de apelación audiencia pública con la presencia del acusado, ya que con carácter general no cabe deducir la misma relevancia de la comparecencia personal del acusado en primera instancia y en apelación, como tampoco cabe deducir automáticamente la audiencia pública ni la comparecencia personal de la fase de apelación ${ }^{19}$. Aunque en este ámbito no resulta fácil dirimir cuando se está resolviendo sobre el acceso al recurso y la defensa por el recurrente y cuestiones como la inmediación en la apreciación de la prueba en esta segunda instancia nacional ${ }^{20}$.

Esta enumeración de antecedentes significativos en la jurisprudencia de Estrasburgo se completa con la referencia al Caso Constantinescu contra Rumanía ${ }^{21}$, frente a una condena revocatoria en apelación de una sentencia anterior absolutoria, en la que no se había llevado a cabo una audiencia personal del acusado en la que se declaró la vulneración del art. 6.1 CEDH.

\section{EL CONTEXTO INTERNO}

En este contexto, la realización de la actividad probatoria dentro de un conjunto de garantías que han de observarse a lo largo del proceso, constituye una exigencia para la fundamentación de la pena dentro del proceso contradictorio. Pero estos principios reiterados en la jurisprudencia constitucional pueden plantear algunas dificultades respecto a

16 STEDH de 25 de abril de 1983, STEDH de 8 de diciembre de 1983 y STEDH de 24 de febrero de 1984.

17 STEDH de 12 de febrero de 1985.

18 STEDH de 26 de mayo de 1988.

19 Entre otros Caso Kremzow contra Austria, STEDH de 21 de septiembre de 1993, Caso Botten contra Noruega, STEDH de 19 de febrero de 1996, Caso Belziuk contra Polonia, STEDH de 25 de marzo de 1998.

20 Carmona Ruano, M., «El derecho al recurso en los dictámenes del Comité de Derechos Humanos de las Naciones Unidas y las sentencias del Tribunal Europeo de Derechos Humanos» en Estudios de Derecho Judicial, n. ${ }^{\circ} 96$, Op. Cit., p. 438.

21 STEDH de 27 de junio de 2000. 
su observancia cuando son contextualizados ${ }^{22}$. Se trataría de determinar si la exigencia de la inmediación conlleva la práctica nuevamente de todas las pruebas en segunda instancia, o tan solo de aquéllas de carácter personal (audiencia de acusado, testigos y peritos), por cuanto puede suponer una «restricción de la oralidad y publicidad que se produce en el caso de que no se celebre vista oral» ${ }^{23}$.

Es cierto que el legislador, a través de sucesivas reformas, ha introducido el recurso de apelación para procedimientos penales singulares, pero en todo caso estamos ante una previsión acotada claramente. A este respecto, cabe recordar que no existe controversia en los supuestos en los que procede interposición del recurso de apelación, ni tampoco a las posibilidades de proponer prueba, limitándose claramente la proposición de prueba a tres supuestos muy concretos. En efecto, cuando no constituya una reiteración de la ya practicada en primera instancia y, por tanto, no se hubieran practicado entonces aquellas otras que hubieran sido «indebidamente» denegadas y constara expresamente la intención de reiterar su práctica en el recurso ulterior de apelación y, finalmente, aquellas que pese a haber sido admitidas, no se pudieron practicar sin que la imposibilidad de su práctica sea imputable al solicitante.

Hemos de reparar inicialmente en las características que rodean a la apelación en nuestro sistema judicial, de tal modo que si no existe una previsión legal entorno a la realización integra de la prueba en apelación, los términos en los que se haya sustanciado la prueba en primera instancia pueden ser relevantes a la hora de concretar el cambio de criterio y, por tanto, de fallo del tribunal de apelación de carácter condenatorio, frente al de instancia previo que hubiera resultado absolutorio. El análisis de la importancia de la vista oral debe encardinarse dentro de la práctica de la prueba y con especial énfasis en aquellos procedimientos que habiendo concluido con sentencia absolutoria en primera instancia son recurridos en apelación, tras la realización de una valoración diferente de la credibilidad de testimonios (declaraciones de los acusados o declaraciones testificales) «en la que se fundamenta la modificación del relato de hechos probados y la conclusión condenatoria, medios de prueba que, por su carácter personal, no podían ser valorados de nuevo sin inmediación, contradicción y publicidad» (STC 167/2002).

\section{EL PRINCIPIO DE INMEDIACIÓN}

En concreto hemos de reflexionar sobre si el denominado derecho al recurso o a la doble instancia penal, pese a su carácter limitado ¿Debe de tener un contenido mínimo?

$22 \mathrm{El}$ punto de partida en este análisis puede ser el de un entendimiento «finalístico» del derecho a la tutela judicial efectiva que conduce necesariamente desde la perspectiva teleológica al alto Tribunal a «la interdicción de la indefensión, y dicha indefensión, desde un enjuiciamiento general, no se produce cuando, (...) las pretensiones del acto han sido examinadas y resueltas conforme a Derecho por dos órganos judiciales distintos (...) ninguna vulneración comporta per se la declaración de un pronunciamiento condenatorio en segunda instancia, sin que por ello resulte constitucionalmente necesaria la previsión de una nueva instancia de revisión en una cadena de nuevas instancias que podría no tener fin « (STC 60/2008).

23 »debe favorecerse la celebración de vista en apelación, ya que la oralidad no debe quedar mermada, en la segunda instancia, por una errónea prevalencia de la celeridad mal entendida o de un criterio de oportunidad, que no pueden prevalecer frente a la necesidad de un proceso justo, celebrado en audiencia pública y rodeado de las garantías legales, igualmente observable en el recurso de apelación». Rifá Soler, J. M., Valls Gombau, J. F., Richard González, M., El Proceso Penal Práctico, Comentarios, jurisprudencia, formularios, Sexta edición, La Ley, p. 958. 
y, si dentro de éste ¿Tendría que estar contenida la audiencia pública? Por tanto, la duda que surge es ¿Cuál ha de ser el nivel de exigencia de una audiencia pública en la segunda instancia penal? ¿Nace esta exigencia de nuestro propio ordenamiento o más bien es una aportación del derecho internacional de los derechos fundamentales?

Es por esta razón que la prohibición de la indefensión conlleva que se exija a los órganos jurisdiccionales una especial diligencia, «con el fin de preservar el derecho de defensa de las partes», debiendo respetarse en el proceso la contradicción entre las partes al objeto de disponer de las mismas "posibilidades de alegación y prueba en el ejercicio de su derecho de defensa a lo largo de todas sus instancias» (STC 199/2006).

Evidentemente tenemos que referirnos a la audiencia pública del posteriormente condenado, toda vez que la inmediatez se constituirá en esta materia en principio de obligada observación. En efecto, considerada esta situación en abstracto cabría pensar que carecería de justificación suficiente la condena de quien hubiese sido absuelto en primera instancia con base en «los resultados de pruebas personales» que no hubieran sido objeto de práctica «directa e inmediata» ante el Tribunal ad quem, siendo oído esencialmente el acusado, pero acaso también los testigos y los peritos ${ }^{24}$. Ahora bien, la cautela se impone, de un lado porque no se trata de generalizar la práctica de la vista oral en la segunda instancia. En segundo lugar, porque la especial trascendencia para la resolución del caso se puede encontrar en la práctica de la audiencia pública del procesado, pero no con carácter general, como una nueva exigencia que se impusiese por el Tribunal de Estrasburgo al juez ordinario, sino porque atendiendo a las circunstancias concretas que concurran, procede para garantizar los derechos de defensa del procesado, llevar a cabo dicha audiencia pública para que sea escuchado en segunda instancia.

Recordemos que podrá acordarse la vista a tenor del art. 791 LECRIM, previa solicitud que se contenga en el escrito de interposición del recurso y haya sido admitida por la Audiencia. Así como cuando la Sala bien de oficio, o a instancia de parte, considere su necesidad para la correcta formación de una convicción fundada. La pertinencia del acuerdo de convocatoria de vista pública por parte del órgano de apelación ha centrado diversos recursos inicialmente en amparo ante el TC y, posteriormente, ante el Tribunal Europeo en la medida en la que la denegación de dicha vista pública pudiera constituir una vulneración del principio de inmediación y, por consiguiente, una vulneración de la tutela judicial efectiva ya que se le ha privado de poder ejercer debidamente la defensa.

La denegación de la vista podría conllevar pues una situación material de indefensión. Como se constata en diversas demandas de amparo ante nuestro alto Tribunal, la inmediación se ha invocado como inherente a la valoración de las pruebas testifical y declaración del acusado, con carácter «inexcusable» para el órgano sentenciador (gestos, estado de ánimo, seguridad, actitud..). En todo caso, será preciso concretar el contexto en el que tiene lugar dicha petición de vista pública, ya que si el objetivo es la observancia del principio de inmediación en la valoración de la prueba conducente al fallo condenatorio ulterior, parece evidente su relevancia. Ahora bien, para analizar esta cuestión en sus justos términos, hemos de constatar la evolución operada por la jurisprudencia del propio Tribunal Constitucional fundamentada, sin duda, en la jurisprudencia del Tribunal de Estrasburgo.

24 Montón Redondo, A., Derecho Jurisdiccional III, Proceso Penal, Tirant lo blanch, Valencia 2010, p. 389 . 
En efecto, la jurisprudencia del TEDH recoge como la exigencia del proceso justo o equitativo «implica, en principio, la facultad del acusado de estar presente y ser oído personalmente en la primera instancia». Ahora bien, no existe una exigencia igual con carácter absoluto en la fase de apelación ${ }^{25}$. A tenor de la jurisprudencia del Tribunal Europeo cabe resumir la exigibilidad de la segunda instancia de forma casuística ya que será necesario, de un lado, tener en cuenta las peculiaridades del procedimiento concreto en el que se plantee. De otra parte, el lugar que la legislación interna prevé para la jurisdicción de apelación. Además será determinante «la manera en la que los intereses del demandante fueron realmente expuestos y protegidos ante el Tribunal a la vista de las cuestiones que éste tiene que juzgar» ${ }^{26}$. En resumen, procederá la exigencia de audiencia pública en el recurso de apelación, atendiendo a las circunstancias del caso y las características del procedimiento interno.

Es en este sentido en el que el TEDH ha puntualizado que «la ausencia o falta de una vista o debates públicos en segunda o tercera instancia puede justificarse por las características del procedimiento de que se trate, con tal que se hayan celebrado en la primera instancia». Así lo ha admitido el Tribunal Europeo respecto a los procedimientos para autorizar la interposición de la apelación o consagrados exclusivamente a cuestiones de derecho y no a las de hecho, en relación con las cuales ha señalado que se cumplirán los requisitos del art. 6.1 del Convenio aunque el Tribunal de apelación o casación no haya dado al recurrente la facultad de ser oído personalmente ${ }^{27}$.

La reiterada jurisprudencia del Tribunal de Estrasburgo descansa en que «es la naturaleza de las cuestiones a tratar ante la jurisdicción de apelación la que determinará la necesidad de que se celebre una vista pública», de tal modo que «la celebración de una vista pública en apelación será exigible cuando la valoración de las pruebas de naturaleza personal (testimonios) sea determinante para decidir sobre la culpabilidad del demandante, exigiendo estas pruebas, por su propia naturaleza, un conocimiento directo e inmediato por el Tribunal de apelación». Además, se concreta por el TEDH en esta sentencia que en «un Tribunal de apelación que goza de la plenitud de jurisdicción, el artículo 6 no garantiza necesariamente el derecho a una vista pública ni, si dicha vista ha tenido lugar, el de asistir en persona a los debates».

Por tanto, se hace necesario un ejercicio de concreción, a los efectos que aquí interesan, ya que no existe un pronunciamiento de alcance general sobre esta cuestión por el Tribunal de Estrasburgo, sino la exigencia de acudir a la casuística para precisar el alcance concreto en el asunto sometido a la consideración del Tribunal. Así, se recoge en dicha jurisprudencia que «cuando el Tribunal de apelación ha de conocer tanto de cuestiones de hecho como de derecho, y en especial cuando ha de estudiar en su conjunto la culpabilidad o inocencia del acusado», el TEDH ha entendido que «la apelación no se puede resolver en un proceso justo sin un examen directo y personal del acusado que niegue haber cometido la infracción considerada punible, de modo que en tales casos el nuevo

25 «No se puede concluir, por lo tanto, que como consecuencia de que un Tribunal de apelación esté investido de plenitud de jurisdicción, tal circunstancia ha de implicar siempre, en aplicación del art. 6 del Convenio, el derecho a una audiencia pública en segunda instancia, independientemente de la naturaleza de las cuestiones a juzgar».

26 Caso Tierce y otros contra San Marino, STEDH de 25 de julio de 2000.

27 Caso Tierce y otros contra San Marino, STEDH de 25 de julio de 2000. 
examen por el Tribunal de apelación de la declaración de culpabilidad del acusado exige una nueva y total audiencia en presencia del acusado y los demás interesados o partes

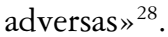

No ignora el alto Tribunal que las demandas que han sido promovidas ante el Tribunal de Estrasburgo por infracción del art. 6.1 del Convenio, en el caso de sentencias de apelación en procedimientos penales, tienen su fundamentación en la hipotética vulneración de la inmediación, ya que no tuvo lugar en segunda instancia la audiencia o vista oral. En efecto, el TEDH ha declarado «con carácter general, que el proceso penal constituye un todo, y que la protección que dispensa» el art. 6.1 del Convenio «no termina con el fallo en la primera instancia, de modo que el Estado que organiza Tribunales de apelación tiene el deber de asegurar a los justiciables, a este respecto, las garantías fundamentales del art. 6.1 $\mathrm{CEDH}^{29}$.

\section{LOS PRONUNCIAMIENTOS DEL TEDH CONDENATORIOS AL ESTADO ESPAÑOL}

Brevemente procedemos al análisis de los casos de los que ha tenido conocimiento el Tribunal Europeo como consecuencia de la demanda al Estado español por vulneración del citado precepto del Convenio. El análisis de estos asuntos permite constatar el parámetro que emplea el Tribunal de Estrasburgo.

En todo caso, las fronteras que delimitan esta jurisprudencia convencional no terminan de quedar claramente dibujadas, ya que como el propio TEDH ha señalado y nuestro alto Tribunal ha reiterado, «las modalidades de aplicación del art. 6 del CEDH a los procesos de apelación dependen» en primer lugar de las características del propio proceso así como las relativas a la jurisdicción de apelación en cada ordenamiento jurídico nacional. Por tanto, no hay un reconocimiento expreso y para todos los casos de la necesidad de llevar a cabo una vista pública en segunda instancia, si no que se habrá de estar a las particularidades del proceso y especialmente a «la manera en que los intereses del demandante han sido realmente expuestos y protegidos en ella, y principalmente la naturaleza de las cuestión que zanjar».

Así el origen de la resolución en el Caso Bazo González ${ }^{30}$, está en la sentencia de primera instancia que fue absolutoria por el Juzgado de lo penal, si bien se planteó con posterioridad el recurso de apelación por el Ministerio fiscal como por el Abogado del Estado. Es relevante que en segunda instancia ninguna de las partes solicitase la celebración de vista pública. La Audiencia Provincial, sin modificar los hechos dicta sentencia condenatoria por tentativa de delito de contrabando, al entender que «la interpretación de la ley (...) realizada por el tribunal a quo fue errónea», si bien, no se llevó a cabo ninguna modificación de los hechos declarados probados. Planteado el recurso de amparo el TC resolvió que no resultaba exigible la celebración de la vista pública.

El correcto entendimiento de las exigencias derivadas de la jurisprudencia del TEDH no es otro que el que le permite a nuestro alto Tribunal concluir que «como

28 Caso Constantinescu contra Rumanía, STEDH de 27 de junio de 2000.

29 Caso Tierce y otros contra San Marino, STEDH de 25 de julio de 2000.

30 STEDH de 16 de diciembre de 2008. 
consecuencia de que un Tribunal de apelación esté investido de plenitud de jurisdicción, tal circunstancia ha de implicar siempre, en aplicación del art. 6 del Convenio, el derecho a una audiencia pública en segunda instancia, independientemente de la naturaleza de las cuestiones a juzgar», por lo que si «la celebración de una vista pública no era indispensable» y el órgano juzgador «se limitó a efectuar una interpretación diferente a la del Juez a quo», no resultó necesaria una vista pública, por lo que concluye el Tribunal de Estrasburgo que no se vulneró el derecho del demandante a beneficiarse de un proceso justo.

En el Caso Igual Coll, tras la sentencia absolutoria del Juzgado de lo Penal relativa a un delito de abandono de familia, con ocasión del recurso de apelación por la ex esposa, se solicita la celebración de vista pública. La Audiencia Provincial deniega esta petición y posteriormente dicta sentencia condenatoria por delito de abandono de familia, admitiendo los hechos declarados probados por el tribunal a quo. Agotada la vía judicial previa, se interpone recurso de amparo ante el TC que no prospera, al entender éste que en primera instancia ya fueron objeto de debate y examen las pruebas propuestas, y que en la Audiencia simplemente se dictaminó la culpabilidad con fundamento en los hechos considerados probados en primera instancia de forma motivada y sin arbitrariedad.

A continuación, se interpone demanda ante el Tribunal de Estrasburgo que tendrá ocasión de reiterar como un Tribunal de apelación goza de plena jurisdicción, y, por ello, »el artículo 6 no garantiza necesariamente el derecho a una vista pública ni, si dicha vista ha tenido lugar, el de asistir en persona a los debates». Ahora bien, reiterando jurisprudencia anterior se afirma por el TEDH que «cuando una instancia de apelación debe conocer un asunto de hecho y en derecho y estudiar en su conjunto la cuestión de la culpabilidad o de la inocencia, no puede, por motivos de equidad del proceso, decidir estas cuestiones sin valoración directa de los medios de prueba presentados en persona por el acusado que señala que no ha cometido el acto considerado delito penal» ${ }^{31}$.

En el Caso Marcos Barrios ${ }^{32}$ el origen de esta demanda ante el Tribunal de Estrasburgo está en el procedimiento penal en el que el Juez de lo penal absuelve de un delito de asesinato por las contradicciones parciales de un testigo, así como por insuficiencia de otras pruebas de cargo. El Ministerio Fiscal y la acusación particular recurrieron, solicitando una vista pública en la que se pudieran valorar algunas pruebas. Por la Audiencia Provincial no se admitió dicha propuesta, procediéndose a un pronunciamiento sobre la veracidad y credibilidad de las declaraciones de un testigo que conllevó la modificación de los hechos declarados probados por el Juzgado de lo penal, con la consiguiente sentencia condenatoria. Tras plantearse el recurso de amparo, el Tribunal Constitucional entendió que no concurrían las circunstancias adecuadas de conformidad con la STC 167/2002, y que tan sólo se había producido una variación en el valor atribuido a las declaraciones de un testigo. Interpuesta la demanda ante el TEDH, se resolverá por éste concluyendo la vulneración del art. 6.1 CEDH, al entender que «la condena en apelación (...) tras un

31 En relación con el margen legal que permite la legislación procesal entiende el Tribunal Europeo que «la Audiencia no se limitó a efectuar una interpretación diferente en derecho a la del Juez a quo respecto a un conjunto de elementos objetivos, sino que efectuó una nueva apreciación de los hechos probados en primera instancia y los reconsideró, cuestión que va más allá de las consideraciones estrictamente jurídicas». Por estas razones el TEDH entiende que la condena adoptada por la Audiencia Provincial, sin haber sido oído personalmente, no se adecua a «las exigencias de un proceso justo garantizado por el art. 6.1 del Convenio». STEDH de 10 de marzo de 2009.

32 STEDH de 21 de septiembre de 2010. 
cambio en la valoración de las declaraciones en litigio (...) sin que el demandante tuviera ocasión de ser oído personalmente y rebatirlas mediante un examen contradictorio en una vista pública, no es conforme con las exigencias de un proceso equitativo».

En el Caso García Hernández ${ }^{33}$, se inicia este procedimiento judicial con una resolución de absolución en un procedimiento por presunto delito de lesiones por imprudencia profesional. El recurso de apelación fue interpuesto por el afectado y la Audiencia Provincial resolvió mediante sentencia que dictó sin celebración de vista pública, estimando el recurso y condenando como autora responsable de una falta de lesiones por imprudencia leve. El recurso de amparo fue inadmitido por carecer de contenido constitucional, al considerar el TC que la condena no se «había basado en una nueva valoración de las pruebas practicadas en el juez a quo, sino en una distinta apreciación jurídica de los hechos».

Interpuesta la demanda ante el TEDH, en la sentencia que resuelve el caso se afirma que la «Audiencia Provincial no se limitó a una nueva valoración de cuestiones puramente jurídicas, sino que se pronunció sobre la mala praxis de la demandante y el origen de las secuelas del paciente, modificando así los hechos declarados probados por el Juzgado de primera instancia» ${ }^{34}$. Por tanto, el examen efectuado por la Audiencia Provincial, hacía necesaria la celebración de una vista pública ante el órgano de apelación.

El Caso Almenara Álvarez ${ }^{35}$ tiene su origen en un procedimiento penal por malversación de bienes que concluye en primera instancia con sentencia absolutoria, si bien recurrida dicha absolución en apelación, el órgano jurisdiccional lleva a cabo una modificación de los hechos probados tras una nueva valoración de las pruebas que se practicaron en la primera instancia. En efecto, la Audiencia Provincial anuló la sentencia de instancia y condenó a la demandante por alzamiento de bienes. El sucesivo recurso de amparo fue inadmitido por el alto Tribunal dada su inexistente relevancia constitucional. Sin embargo, una vez instado el enjuiciamiento por el Tribunal de Estrasburgo, éste reiteró la necesidad de haber llevado a cabo el juicio oral dada la valoración diferenciada que de las pruebas se hizo en segunda instancia ${ }^{36}$, constatando pues la vulneración del art. 6.1 del CEDH.

Aun cuando el desarrollo del procedimiento en el ámbito interno difiere, en el Caso Valbuena Redondo ${ }^{37}$, reúne también las condiciones que están siendo aquí objeto de consideración. En este caso, se trata de un procedimiento penal en el que en primera instancia se dictó sentencia absolutoria al no apreciarse por el Juzgado de lo penal, en atención a las pruebas que obraban en autos, la existencia de ánimo defraudatorio y, en todo caso, tan sólo meras infracciones administrativas. Pero tras el recurso de apelación formulado por el Abogado del Estado al que se adhirió el Ministerio Fiscal y, sin que ninguna de las partes interesara la vista oral, se condenó por dos delitos contra la Hacienda Pública

33 STEDH de 16 noviembre de 2011.

34 «tal examen implica, por sus características, posicionarse ante unos hechos decisivos para la determinación de la culpabilidad del demandante. (...) la condena de la demandante (...) tras modificar la valoración de elementos tales como el comportamiento de la demandada, sin que ésta tuviera la posibilidad de ser oída personalmente y someterlos a contradicción en la vista pública, no es conforme con las exigencias del juicio justo que garantiza el art. 6.1.» 35 STEDH de 25 de octubre de 2011.

36 «tras un cambio en la valoración de elementos tales como sus intenciones y su comportamiento, que han sido decisivos para la declaración de culpabilidad, sin que la demandante haya tenido la ocasión de ser oída personalmente».

37 STEDH de 13 de diciembre de 2011. 
cometidos por medio de un delito de falsedad en documento público (escrituras de compraventa) y de un delito de falsedad en documento comercial (facturas falsas).

El ulterior recurso de amparo ante el TC se fundamenta en la vulneración de la tutela judicial efectiva, ya que en la Sentencia de la Audiencia Provincial, más allá de llevarse a cabo «una nueva calificación jurídica de los hechos», se procedió a la valoración de cuestiones de hecho que se habían considerado probadas en la primera instancia. Sin embargo, por parte de nuestro alto Tribunal se declaró inadmisible dicho recurso por carecer de relevancia constitucional.

Tras la interposición de la demanda ante el TEDH en la resolución del caso se puntualiza que en el enjuiciamiento llevado a cabo por la Audiencia Provincial, se efectuó un pronunciamiento expreso sobre la existencia de voluntad de defraudar a la Hacienda Pública, lo que constituye una manifestación relativa a una cuestión de hecho, por lo que se procedió a llevar a cabo una modificación de los hechos declarados probados en primera instancia tan solo a tenor de la prueba documental y sin que el condenado «hubiere tenido la oportunidad de ser oído personalmente y de discutirlos mediante un examen contradictorio en el curso de una vista oral», lo que no es conforme a las exigencias de un proceso equitativo.

El Caso Serrano Contreras ${ }^{38}$ tiene su origen en una sentencia de la Audiencia Provincial de carácter absolutorio por falta de pruebas, por considerar este órgano jurisdiccional que no habría quedado acreditado el dolo exigible para la concurrencia del tipo penal. En efecto, el art. $528 \mathrm{CP}$ en ese momento exigía un ánimo defraudatorio que no pudo ser acreditado. La valoración que efectuó la Audiencia Provincial se concretó en la consideración de la imposibilidad de una afirmación rotunda de la falsedad de las etiquetas sino una probabilidad. Una valoración diferente de algunas pruebas llevó al TS a dictar sentencia condenatoria por los delitos de estafa (art. $528 \mathrm{CP}$ ) y falsedad (art. 303 CP). El TS efectuó la modificación parcial de los hechos declarados probados por la Audiencia relativos a los documentos aportados en dos comisiones rogatorias relativos a dos etiquetados de semillas, alcanzando el convencimiento de su falsedad. El demandante alegó la falta de audiencia pública, si bien no fue solicitada por las partes en el juicio oral ante la Audiencia Provincial. Un ulterior recurso de nulidad fue desestimado por el TS por entender que sólo concurriría su oportunidad en el caso del recurso de apelación, pero no de casación que por definición es un recurso extraordinario. El planteamiento a continuación del recurso de amparo fue objeto de resolución de inadmisión del TC por carencia de relevancia constitucional la materia objeto del mismo.

La presentación de la demanda ante el TEDH se sostiene sobre la violación por el Estado español del derecho a la defensa toda vez que fue condenado el demandante por el TS sin posibilidad de ser oído en vista pública y la condena se basó en una nueva valoración de pruebas, no de carácter documental, que se aportaron como consecuencia de las comisiones rogatorias. Para el Tribunal de Estrasburgo «el hecho de que el TS haya tenido en cuenta un medio de prueba que no había sido examinado por el tribunal a quo y que se convirtió en determinante para el establecimiento de la culpabilidad del demandante, privó a éste de la posibilidad de defenderse frente al mismo». 
En el Caso Lacadena Calero ${ }^{39}$, la Audiencia Nacional absolvió del delito de estafa y falsedad en documento público al cónyuge de la demandante ante el TEDH, sin embargo recurrida la sentencia ante el TS por el Abogado del Estado y otros condenados, se dictó sentencia condenatoria. Bien es cierto que se dio audiencia a los letrados y condenados en primera instancia así como a la defensa del cónyuge de la demandante, pero no se llevó a cabo la comparecencia material de éste recurrente que finalmente resultó condenado por complicidad en la estafa. La revisión de hechos que estaba prohibida en casación fue la fundamentación en la que descansó el posterior recurso de amparo. La vulneración de los derechos a un proceso con todas las garantías se habría producido por fundamentarse la condena en «una revisión fáctica que altera sustancialmente los hechos probados». El TC consideró que la actuación llevada a cabo por el TS no constituía una revisión de los hechos probados, sino que tan solo se había limitado a rectificar la inferencia realizada por el Tribunal de instancia con base en unos hechos que habían sido acreditados.

Ante el TEDH se argumentó que se habría vulnerado el derecho al proceso en relación con la falta de inmediación en el caso del recurso de casación. Para el Tribunal de Estrasburgo «el TS extrajo inferencias de la intención del acusado a partir de los hechos declarados probados por la instancia inferior (la prueba documental). Sin embargo, para extraer tal inferencia, el TS no escuchó al interesado, quien no tuvo la oportunidad (inexistente en el proceso de casación) de exponer ante el tribunal las razones por las que negaba ser consciente de la ilicitud de su actuación y la voluntad defraudatoria (...) el acusado no fue oído personalmente sobre una cuestión de hecho determinante para la valoración de su culpabilidad».

En el Caso Vilanova Goterris y Llop García ${ }^{40}$, se trata de dos demandas ante el Tribunal que son acumuladas para su resolución y que tienen origen en la sentencia de la Audiencia Provincial que absolvió al primer demandante de un delito de prevaricación medio ambiental y de otro de denegación de auxilio y al otro demandante de un delito contra el medio ambiente por contaminación acústica. La parte acusadora interpuso recurso de casación que concluyó condenando, sin celebración de vista pública, al primero de ellos por delito de prevaricación medioambiental y al segundo por un delito contra el medio ambiente. Los condenados interpusieron sendos recursos de amparo invocando la vulneración del derecho a la tutela judicial efectiva y el principio de legalidad penal (art. $25 \mathrm{CE}$ ). El alto Tribunal sin embargo, inadmite sendas demandas al entender que las pretensiones contenidas en las mismas carecían de contenido constitucional que justificara una decisión sobre el fondo. Ante el planteamiento de recuso al Tribunal de Estrasburgo éste apreció que el TS llevó a cabo una nueva valoración de los elementos de prueba que habían sido practicados en la vista pública en la Audiencia Provincial, sin haber dado la oportunidad a las partes a ser escuchados en sus alegaciones directamente en el recurso de casación. Concluye el Tribunal de Estrasburgo que ha habido violación del derecho a un juicio equitativo reconocido en el art. 6.1 CEDH.

El Caso Román Zurdo y otros ${ }^{41}$ tiene su origen en la querella interpuesta por el Ministerio Fiscal contra varios concejales como presuntos autores de delitos relativos a la ordenación del territorio por concesión de licencias de obras ilegales. El Juzgado de lo Penal dictó sentencia

39 STEDH de 22 de noviembre de 2011.

40 STEDH de 27 de noviembre de 2012.

41 STEDH de 8 de octubre de 2013. 
absolutoria ya que el delito del art. 320 del CP exige dolo del autor y no quedaba acreditado que los demandados conocieran la ilegalidad de las licencias de obras. Por parte del Ministerio Fiscal como de la acusación particular, se interpuso el recurso de apelación ante la Audiencia Provincial que sin practicar nuevas pruebas ni oir a los demandados llevo a cabo una modificación parcial de los hechos declarados probados por el Juez a quo. En efecto, la Audiencia Provincial resolvió condenar a una pena de doce meses de prisión e inhabilitación para el ejercicio del cargo por un período de 8 años, por un delito contra la ordenación del territorio en su modalidad de corrupción urbanística, por entender que quedaba probado el conocimiento de la ilegalidad de las licencias concedidas por los ahora condenados.

Con posterioridad se interpuso recurso de amparo por vulneración del derecho al proceso equitativo y al principio de la legalidad penal, al no haberse practicado prueba en la Audiencia Provincial y haberse vulnerado el derecho a la presunción de inocencia. El TC no apreció las vulneraciones alegadas considerando que tan sólo por parte de la Audiencia se había llevado a cabo «un cambio en la inferencia» basado en las pruebas documentales y la legislación urbanística aplicable al caso.

Interpuesta la demanda ante el TEDH por vulneración del principio de inmediación, éste concluyó que al haberse pronunciado la Audiencia Provincial sobre «circunstancias subjetivas de los demandantes, a saber, que tenían conocimiento de la ilegalidad de las licencias de obras litigiosas», sin tener conocimiento directo de los testimonios de los demandantes y llevar a cabo una nueva valoración todo ello condujo a la vulneración del art. 6.1 CEDH.

El Caso Nieto Macero ${ }^{42}$ igualmente presenta una inicial sentencia de absolución por el Juzgado de lo penal de un delito de atentado contra la autoridad del que se le acusaba junto a otras tres personas por haber arrojado presuntamente objetos al paso de un vehículo policial. Recurrida la sentencia por los agentes policiales se llevó a cabo el emplazamiento al Ministerio Fiscal y a las partes si bien el demandante no fue personalmente convocado como preceptúa el art. 182 LECRIM, tan sólo su procurador recibió notificación dos días antes de la celebración de la vista en la que si estuvo presente. La Audiencia Provincial dictó sentencia de condena a todos los demandados a una pena de prisión de un año y al pago de una indemnización.

Sucesivamente se planteó por el demandante incidente de nulidad de actuaciones que fue desestimado por improcedente, así como recurso de amparo que no fue admitido por falta de especial trascendencia constitucional.

El recurso planteado ante el TEDH se fundamenta de un lado en la violación del principio de inmediación y consecuentemente del art. $6 \mathrm{CEDH}$ ya que la vista pública se celebró sin ser personalmente emplazado para comparecer el demandado por la Audiencia Provincial, como prescribe el citado art. 182 LECRIM, llevándose a cabo posteriormente por la Audiencia Provincial una modificación de los hechos declarados probados. El Tribunal de Estrasburgo falla la violación del art. 6.1 CEDH, si bien no se manifiesta sobre el resultado de haberse producido la celebración de la audiencia pública con la presencia del demandante, extremo éste que había sido objeto de reclamación en concepto de daño moral.

El Caso Varela Geis ${ }^{43}$ tiene su origen en una condena por el Juzgado de lo penal por delito continuado de genocidio en virtud del art. 607.2 CP, así como por delito continuado

42 STEDH de 8 de octubre de 2013.

43 STEDH de 5 de marzo de 2013. 
de provocación a la discriminación, al odio y a la violencia contra grupos por motivos racistas y antisemitas en virtud del art. 510.1 CP. Recurrida la citada sentencia ante la Audiencia Provincial con fundamento en la profesión de librero del condenado que no editor o distribuidor de las obras antisemitas en las que se había fundado aquella condena y previa vista oral se acordó el planteamiento de una cuestión de inconstitucionalidad relativa a la conducta sancionada por el art. 607.2 $\mathrm{CP}^{44}$. Nuestro Tribunal de garantías constitucionales declaró la inconstitucionalidad de aquel precepto en lo relativo a los términos «que nieguen» delitos tipificados como genocidio. Como consecuencia de esta sentencia, la Audiencia Provincial con expresa mención a su vinculación a la declaración de inconstitucionalidad llevada a cabo por el alto Tribunal relativa al delito de negación de genocidio entiende que deben quedar exentos de sanción penal absolviendo al condenado de dicho delito. Ahora bien, condena a este por el delito de justificación de genocidio (art. 607.2 CP). A continuación se instó demanda para promover el incidente de nulidad de actuaciones que fue rechazado por lo que el condenado presentó recurso de amparo con fundamento en la vulneración del derecho a la tutela judicial efectiva (art. $24 \mathrm{CE}$ ), al principio de legalidad (art. $25 \mathrm{CE}$ ), libertad de pensamiento (art. 16 CE) y libertad de expresión (art. 20), que fue inadmitido por aquél.

La demanda formulada ante el Tribunal de Estrasburgo se fundamenta en el hecho de haber sido condenado en apelación por un delito que no se había incluido inicialmente en el escrito de acusación y por el que no había sido objeto de condena en primera instancia en virtud de lo preceptuado en el art. 6.1 CEDH en orden al derecho a que su causa sea oída equitativamente en conexión con ser informado de la causa de la acusación formulada contra él y disponer de tiempo y facilidades para su defensa (art. 6.3 CEDH). Finalmente se resuelve la vulneración del Convenio y del derecho a ser informado de la naturaleza y la causa de la acusación a la luz del derecho del acusado a preparar su defensa.

Caso Naranjo Acebedo ${ }^{45}$. Los datos relevantes en este asunto se resumen en una sentencia condenatoria inicial por parte de la Audiencia Provincial tras un juicio público con jurado popular condenando por delito de robo con violencia y uso de armas. Recurrida la sentencia por el Ministerio Fiscal y por otros condenados se dictó por el Tribunal Superior de Justicia nueva sentencia absolutoria del delito de tenencia ilícita de armas y condenatoria como coautor de dos delitos de asesinato. Planteado el recurso de casación por haber sido condenado sin previa audiencia por el Tribunal Superior, el Tribunal Supremo desestimó el recurso por entender que el Tribunal Superior tan sólo había llevado a cabo una nueva calificación jurídica de los mismos hechos, sin que esto contraviniere el derecho al proceso equitativo. Con posterioridad se plantea un recurso de amparo con fundamento en la violación del art. $24 \mathrm{CE}$ que es inadmitido por carecer de suficiente trascendencia constitucional.

La demanda ante el Tribunal Europeo se concreta en la vulneración del derecho a ser oído por el Tribunal Superior de Justicia, lo que constituiría una vulneración del art. 6 $\mathrm{CEDH}$. Sin embargo el TEDH considera que el defensor del condenado pudo esgrimir en su defensa ante el citado Tribunal Superior lo que a su interés hubiere convenido y que el Tribunal juzgador tan sólo llevó a cabo una modificación jurídica en la calificación de

44 «La difusión por cualquier medio de ideas o doctrinas que nieguen o justifiquen los delitos» relativos a la destrucción de grupos nacionales, étnicos, raciales, religiosos.

45 STEDH de 22 de octubre de 2013. 
los hechos declarados probados en primera instancia. Por tanto, no se aprecia vulneración del art. $6 \mathrm{CEDH}$ en este asunto.

Caso Sainz Casla ${ }^{46}$ se trata inicialmente de una sentencia absolutoria para el apoderado de la sociedad por el Juzgado de lo Penal respecto de la acusación de cuatro delitos contra la Hacienda Pública, en concurso con un delito de fraude contable relativos a las declaraciones de la renta e IVA entre los años 1988 y 1999. La absolución se produce por ausencia del elemento subjetivo del tipo, esto es la intención de defraudar, en el demandado, si bien dos inculpados si fueron condenados.

Recurrida la sentencia en apelación por el Ministerio Fiscal, Abogacía del Estado y los coinculpados, el demandante se opuso al mismo. La Audiencia Provincial dictó sentencia condenatoria para el demandante, sin haber considerado la necesidad de celebrar audiencia pública, a una pena de prisión y pago de multa. Es cierto que incorporó una nueva calificación a los hechos la existencia de la firma de varios cheques que el ahora condenado había dirigido al banco en su condición de apoderado de la sociedad. La Audiencia consideró que había existido participación directa en la comisión de los delitos a tenor de la declaración de uno de los inculpados y el testimonio de un experto que así lo declararon en audiencia pública celebrada ante el Juez de lo Penal. Igualmente por la Audiencia se consideró la autenticidad de la firma pese a la carencia de peritaje sobre la misma, en suma no se apreció por aquélla que no se hubieran observado las exigencias relativas al principio de inmediación.

Planteado el recurso de amparo invocando el art. 24 CE por vulneración del derecho a un proceso equitativo y a la presunción de inocencia, así como el principio de legalidad (art. $25 \mathrm{CE}$ ), el alto Tribunal declaró inadmisible el mismo por no haber justificado el recurrente la especial trascendencia constitucional.

La demanda ante el TEDH se fundamentaba, entre otras, en la vulneración del art. 6.1 CEDH respecto de la inmediación. Por el Tribunal de Estrasburgo se considera que al revocar la sentencia del Juzgado de lo Penal la Audiencia Provincial, sin haber escuchado personalmente al condenado, presumiendo su conocimiento de las irregularidades contables se ha vulnerado el art. $6 \mathrm{CEDH}$. De tal modo que al realizar «una nueva valoración del elemento subjetivo del delito contra la Hacienda Pública sin que el demandante tuviera la oportunidad de ser oído personalmente con el fin de impugnar, mediante un examen contradictorio, la nueva valoración efectuada por la Audiencia Provincial», no se realizó la necesaria audiencia del demandante en una vista pública.

Caso Porcel Terribas y otros ${ }^{47}$. En esta ocasión tras la sentencia absolutoria en un asunto de corrupción urbanística, tiene lugar en apelación la sentencia condenatoria en base, entre otras, a las declaraciones testificales prestadas en instancia, por lo que se aduce la vulneración de los principios de inmediación y contradicción por parte de la Audiencia Provincial que se habría pronunciado sobre circunstancias subjetivas (la conciencia de la ilegalidad en la conexión de licencias urbanísticas). Interpuesto recurso de amparo por rechazo de incidente de nulidad de actuaciones como por falta de audiencia en apelación, fue inadmitido por Auto en el que se señalaba la falta de invocación de ésta ante la jurisdicción ordinaria, por lo que se resolvía el no agotamiento de la vía previa. El Tribunal de Estrasburgo aprecia que «la jurisdicción de apelación ha reinterpretado los hechos

46 STEDH de 12 de noviembre de 2013.

47 STEDH de 8 de marzo de 2016. 
declarados probados y ha efectuado una nueva calificación jurídica de los mismos, sin respetar las exigencias del principio de inmediación».

Caso Gómez Olmeda ${ }^{48}$. En esta ocasión aunque el demandante fue condenado en instancia por desobediencia grave, fue absuelto de los cargos de calumnia, injuria y encubrimiento. Recurrida en apelación la citada resolución no se llevó a cabo la vista pública ya que no fue solicitada por el condenado, ni acordada por el órgano juzgador, si bien se procedió al visionado de un video del juicio oral en primera instancia. La Audiencia Provincial dictó sentencia condenatoria confirmando la condena por desobediencia grave pero también estimando la autoría de un delito continuado de calumnias. Aunque se planteó por el condenado la nulidad de las actuaciones y con posterioridad recurso de amparo por vulneración del derecho a la tutela judicial efectiva por haber sido condenado sin la posibilidad de previa audiencia pública en la que ejercer su defensa, el Tribunal Constitucional no apreció especial trascendencia constitucional. El Tribunal sin embargo hubo de pronunciarse acerca del visionado del video del juicio oral que para el condenado no podía equivaler a la vista oral en segunda instancia en la que los demandados fueran oídos en la vista de casación, en la que se efectuó una nueva valoración de los hechos, mientras que el Gobierno si defendió su equiparación a los efectos del Convenio, por lo que se concluye que el tribunal de apelación «tenía el deber de tomar medidas positivas» aunque no se hubiese solicitado por el demandante, en orden de la celebración de un juicio oral. Recuerda el Tribunal de Estrasburgo que la jurisprudencia constitucional ya se había hecho eco de que «el visionado de un video de un juicio en primera instancia no capacita a un tribunal de apelación para evaluar testimonios personales».

Caso Atutxa Mendiola y otros ${ }^{49}$. Aun cuando este asunto presenta diversas vicisitudes hemos de reparar a los efectos de la brevedad expositiva en que el Tribunal Superior de Justicia del País Vasco absolvió de un delito de desobediencia a la autoridad a quienes luego recurrirían a Estrasburgo por el que habían sido demandados, por no acatar la resolución del Tribunal Supremo relativa a la disolución de determinados grupos parlamentarios en las instituciones del País Vasco como consecuencia de la declaración de ilegalidad de los partidos políticos Herri Batasuna, Euskal Herritarrok y Batasuna. Recurrida la sentencia en casación el Tribunal Supremo realizó una nueva interpretación jurídica del comportamiento de los demandantes respecto a elementos subjetivos que resultaron determinantes para acordar su culpabilidad en un delito de desobediencia sin que hubieran podido ser oídos ante dicho tribunal. No obstante por parte de cinco magistrados se formuló un voto particular por estimar que se había procedido a una nueva valoración de los elementos de prueba sin la observancia del principio de inmediación. Aunque el Tribunal Constitucional no apreció vulneración del derecho de defensa ${ }^{50}$ si se formuló un

48 STEDH 29 de marzo de 2016.

49 STEDH de 13 de junio de 2017

50 Para la mayoría de los magistrados no «era constitucionalmente exigible que los demandados fueran oídos en la vista de casación», sin embargo en el voto particular se señala que aunque en la segunda instancia no se han modificado «los hechos probados de la sentencia revocada en la parte del relato histórico de los hechos y documentos que lo acreditan, pero sí ha reconsiderado el significado de tales hechos para derivar la presencia del elemento subjetivo de la voluntad de incumplimiento del requerimiento judicial; y en esta reconsideración, se han seleccionado unos datos y excluido otros, (...) lo que propiamente significa también modificarlos porque quedan descontextualizados del conjunto de lo actuado con inmediación en jurisdicción plena en instancia» (STC 205/2013). 
voto particular por cuatro magistrados ${ }^{51}$. Planteado el recurso ante el Tribunal Europeo por éste se resuelve que el Tribunal Supremo debió llevar a cabo una «valoración directa del testimonio de los demandantes» por lo que al no haberse procedido de este modo se les privó de su derecho de defensa en un proceso contradictorio.

\section{LA RECEPCIÓN POR EL TC DE LA JURISPRUDENCIA DEL TEDH}

No cabe la menor duda que esta jurisprudencia aquí reseñada del TEDH ha sido objeto de amplia recepción por el TC y recogida en la reciente reforma de la LECRIM $^{52}$ y ha tenido cabida en la jurisprudencia constitucional, en relación con demandas promovidas por infracción del art. $6.1 \mathrm{del} \mathrm{CEDH}$, «como consecuencia de haberse fallado la apelación de una causa penal sin que se hubiere celebrado en esta fase audiencia o vista pública».

Es cierto que con anterioridad el alto Tribunal había optado por la desestimación de vulneraciones del derecho a un proceso con todas las garantías denunciadas por la «eventual» ausencia de inmediación en la valoración de la prueba por parte del tribunal que resolvía el recurso de apelación en el entendimiento de que no se causaba lesión al derecho fundamental si en apelación no se llevaba a cabo la práctica de nuevas pruebas (STC $120 / 1999)^{53}$. Además desde esta institución se había confirmado que «quien no ha solicitado la práctica de prueba ni la celebración de juicio oral ante el órgano ad quem no puede luego invocar la vulneración del derecho a un proceso con todas las garantías por falta de inmediación, oralidad y contradicción en la fase de apelación» (STC 120/1999).

Se ha producido pues una recepción de la jurisprudencia del Tribunal Europeo en materia de inmediación. Así nuestro Tribunal de garantías constitucionales ha dado entrada a la celebración de la vista pública en segunda instancia, al objeto de propiciar un conocimiento directo e inmediato de las pruebas por parte del órgano judicial encargado de conocer del recurso de apelación, cuando el recurso tuviere por objeto esencial cuestiones de hecho suscitadas por la violación o ponderación de pruebas personales de las que dependa la condena o absolución del acusado, un escenario no tan infrecuente en nuestra actividad jurisdiccional.

Esta evolución jurisprudencial se constata en su primera fase, como se recoge en el ATC 220/1999, cuando se declara por el alto Tribunal que la falta de celebración de vista

51 Se señala la jurisprudencia del Tribunal de Estrasburgo en contrario y se apela a recientes condenas del mismo (Vilanova Goterris o Román Zurdo).

52 »la sentencia de apelación no podrá condenar al encausado que resultó absuelto en primera instancia ni agravar la sentencia condenatoria que le hubiera sido impuesta por error en la apreciación de las pruebas» (art. 792.2).

53 El TC ha señalado que como «consecuencia de la eventual falta de inmediación de la valoración de la prueba por el órgano de apelación, al considerar que no se lesionaba $<$ tal principio en la apelación no se practicaron nuevas pruebas, para lo que efectivamente hubiera sido necesario respetar los principios de inmediación y contradicción > en la segunda instancia penal, sin que nada se pueda oponer a <una resolución que, a partir de una discrepante valoración de la prueba, llega a una conclusión distinta a la alcanzada en primera instancias, pues el Juez ad quem, tanto por lo que respecta a la subsunción de los hechos en la norma, como por lo que se refiere a la determinación de tales hechos a través de la valoración de la prueba se halla en idéntica situación que el Juez a quo y, en consecuencia, puede valorar las pruebas practicadas en primera instancia, así como examinar y corregir la ponderación llevada a cabo por el juez a quo» (STC 129/1999, 43/1997 y 172/1997). 
en el recurso de apelación penal en relación con la garantía procesal contenida en el art. 6.1 $\mathrm{CEDH}$ «afecta al sistema legal de recursos establecido cuando hay, como sucede entre nosotros, más de una instancia y en la apelación se puede ver de nuevo todas las cuestiones», aunque finalmente no se admitiera la demanda de amparo, ya que la condena en segunda instancia se produjo tras la absolución en la primera, porque el Tribunal ad quem dedujo la culpabilidad «de la valoración de la prueba documental y no de otras pruebas, testificales o periciales, que exigían inmediación y oralidad».

En efecto, esta línea jurisprudencial elaborada por el Tribunal de Estrasburgo ha tenido eco a partir de la STC 167/2002, que ha incorporado los elementos integrantes de la misma y reiterado en sucesivas sentencias. El TC en esta resolución reconoce que «ha resultado vulnerado el derecho a un proceso con todas las garantías, al haber procedido la Audiencia provincial a revisar y corregir la valoración y ponderación que el Juzgado de lo penal había efectuado de las declaraciones de los recurrentes en amparo, sin respetar los principios de inmediación y contradicción».

La cuestión que hemos de abordar a continuación no es otra que, en los términos empleados por el alto Tribunal, la relativa a «determinar si en este caso el órgano de apelación podía proceder a revisar y corregir la valoración y ponderación que el órgano judicial de instancia había efectuado de las declaraciones de los acusados, sin verse limitado por los principios de inmediación y contradicción». La cuestión también puede ser formulada en los siguientes términos: «si el contenido del derecho fundamental a un proceso con todas las garantías (art. 24.2 CE), entre las que se integra la exigencia de inmediación y contradicción, puede encontrarse un límite que opera la revisión de la valoración de la prueba por el órgano llamado a decidir en los recursos de apelación y si tal posible límite se ha respetado» en el caso concreto objeto de recurso de amparo (STC 167/2002). Nuestro Tribunal de garantías constitucionales advierte del alcance del enjuiciamiento que está llamado a realizar, pues precisa que «la dificultad que puede suscitar (...) relativa a la interpretación constitucionalmente conforme del art. 795 LECRIM $^{54}$ en relación con el art. 24.2 CE, no es evidentemente la misma en la aplicación de dicho artículo 795 LECRIM al caso actual, que la que pudiera suscitarse en el caso de sentencias condenatorias en primera instancia y en los recursos de apelación contra ellas». Cuestión esta que si bien no ha sido abordada ni por el TC ni ante el Tribunal de Estrasburgo contra el Estado español, es factible que pudiera suscitarse en un futuro no muy lejano.

Pues bien, el propio Tribunal se interroga sobre la «interpretación constitucionalmente conforme del art. 795 de la LECRIM en relación con el art. 24.2 CE» en el caso de sentencia absolutoria en primera instancia y el recurso de apelación contra ella interpuesto y resuelto con sentencia condenatoria. En la medida en que en el contenido del art. 24.2 CE se encuentra, entre otras garantías, la de exigencia de inmediación y contradicción, se debe resolver si «puede encontrarse un límite para la revisión de la valoración de la prueba por el órgano llamado a decidir el recurso de apelación» (STC 167/2000). La jurisprudencia del TC en esta materia inicialmente había procedido a la desestimación de los recursos de amparo por vulneraciones del derecho a un proceso con todas las garantías.

El giro esencial en la doctrina del TC se produce desde el momento en el que se afirma que el Tribunal de apelación «no puede, por motivos de equidad del proceso,

54 En el que se regula el recurso de apelación en el procedimiento abreviado. 
decidir esas cuestiones sin la apreciación de los testimonios presentados en persona por el propio acusado que sostiene que no ha cometido la acción considerada infracción penal (...) excluye que la ausencia de hechos nuevos sea suficiente para justificar la excepción a la necesidad de debates públicos en apelación en presencia del acusado, debiendo tenerse en cuenta ante todo la naturaleza de las cuestiones sometidas al Juez de apelación» (STC 167/2002). En cambio, no será precisa esta inmediación cuando el objeto de la revisión penal no recaiga sobre la veracidad de los hechos. Es decir, si la cuestión versa sobre la aplicación correcta de las reglas que han permitido la conformación del relato incriminatorio, la declaración de culpabilidad y la imposición de la pena.

En el mismo sentido y de conformidad con la jurisprudencia de Estrasburgo, se ha asumido por el TC que respecto de la prueba documental, ésta es susceptible de valoración ulterior en segunda instancia, sin que sea necesario reproducir el debate procesal y, por tanto, no precisando inmediación ${ }^{55}$. Tras el giro jurisprudencial producido con la STC 167/2002, justificada con expresa declaración en el art. 13 de la propia LOTC ${ }^{56}$, a continuación se ha reiterado en numerosas resoluciones que el órgano de apelación «no puede, sin celebración de una vista valorar una prueba de carácter personal y la prueba testifical o la declaración de un acusado. En efecto, esto sería contario a los principios de publicidad, inmediación y contradicción, que conforman parte del derecho a un proceso con todas las garantías» (STC 232/2002).

La recepción por nuestro alto Tribunal de esta orientación jurisprudencial del TEDH se reitera desde el momento en que se ha afirmado por aquél, como se convierte en elemento central la realización de «una nueva valoración de la prueba testifical y de la declaración del acusado, que si tiene lugar sin audiencia pública puede constituir una contravención de los principios de inmediación y contradicción, que podría provocar la lesión del derecho a un proceso con todas las garantías» (STC 134/2007).

Por tanto, a tenor de la jurisprudencia del Tribunal Europeo si el órgano jurisdiccional que conoce del recurso de apelación debe atender para su resolución «cuestiones de hecho como de Derecho y en especial, cuando ha de estudiar en su conjunto la culpabilidad o inocencia del acusado», se hace necesario llevar a cabo «un examen directo y personal del acusado que niegue haber cometido la infracción considerada punible», al objeto de la estricta observancia de los principios que rigen un proceso justo. En este caso se hace precisa «una nueva y total audiencia en presencia del acusado y los demás interesados o partes adversas».

Si bien no cabe deducir con carácter general que al estar investido el tribunal de apelación de «plenitud de jurisdicción» se debe «siempre» deducir «el derecho a una audiencia pública en segunda instancia» como una obligación dimanante del art. 6 CEDH, al margen de las circunstancias que concurran en la litis correspondiente.

Claro que de la propia jurisprudencia del TC se desprende que se debe acreditar que la privación de la vista en la segunda instancia produjo un efectivo y real menoscabo de

55 No existe violación del derecho a un proceso justo cuando no se reproduce el debate público con inmediación en la apelación en los supuestos en los que «no se plantea ninguna cuestión de hecho o de derecho que no pueda resolverse adecuadamente sobre la base de los autos (STC 230/2002).

56 «es conveniente rectificar la jurisprudencia antes aludida (...) para adaptar más estrictamente la interpretación constitucional del derecho fundamental a un proceso con todas las garantía, en cuanto a lo que ahora nos ocupa, las exigencias del Convenio..» 
su derecho de defensa. El recurrente en amparo deberá precisar, bien las alegaciones que pudo esgrimir en la vista oral o «la oposición que no pudo efectuar frente a las alegaciones formuladas por la acusación, al no haberse llevado a efecto la vista oral, así como con el consiguiente perjuicio que para sus intereses se derivó» (STC 363/1993).

Otra muestra de la «inflexión» de la jurisprudencia constitucional en la materia la encontramos, entre otras, en la resolución de un recurso de amparo en el que se denuncia la vulneración del proceso con todas las garantías de un lado, por la necesidad de que se practiquen en apelación de nuevo las pruebas de carácter personal y, de otro, la exigencia de la audiencia al acusado en segunda instancia, a los efectos de su defensa, ya que la sentencia de apelación resultó condenatoria revocando la absolutoria de instancia. Pues bien, con fundamentación en la jurisprudencia del TEDH se concluye la vulneración del derecho fundamental de defensa del recurrente, pues «los intereses del demandante no fueron enteramente protegidos a lo largo del proceso», aunque no se solicitase la celebración de la vista en la fase de apelación la Audiencia Provincial «venía obligada a salvaguardar su derecho de audiencia antes de ser condenado» (STC 184/2009 ${ }^{57}$ ).

Hay que recordar como el propio Tribunal ha afirmado que «no ha venido a cuestionar por constitucionalmente insuficiente el ámbito de la apelación penal en nuestro ordenamiento", sino la observancia de las garantías constitucionales, pero si concluye que la presencia del acusado en el juicio de apelación, cuando en el mismo se debaten cuestiones de hecho que afectan a su declaración de inocencia o culpabilidad, «es una concreción del derecho de defensa que tiene por objeto posibilitar que quien ha sido absuelto en primera instancia pueda exponer, ante el Tribunal llamado a revisar la decisión impugnada, su versión personal sobre su participación en los hechos que se le imputan. Es precisamente el carácter personalísimo de dicha manifestación lo que impone su citación para ser oído» (STC 201/2012 ${ }^{58}$ ).

Pero es con ocasión de la condena en segunda instancia por delito societario con revocación de la sentencia absolutoria de instancia que se aborda la valoración de pruebas no practicadas ante el tribunal de apelación, así como por no haber sido oído por éste con carácter previo a la condena (STC 88/2013). Pues bien, para la resolución de este recurso de amparo el TC se cuestiona el alcance de las garantías procesales en la segunda instancia penal, para afirmar con sustento en la jurisprudencia del TEDH que la observancia de los principios de publicidad, inmediación y contradicción, integrantes del contenido del derecho a un proceso con todas las garantías, «impone inexorablemente que toda condena articulada sobre pruebas personales se fundamente en una actividad probatoria que el órgano judicial haya examinado directa y personalmente en un debate público, en el que se respete la posibilidad de contradicción» 59 .

57 «pues se debe considerar que ha resultado vulnerado el derecho a un proceso con todas las garantías, al haber procedido la Audiencia Provincial a revisar y corregir la valoración y ponderación que el Juzgado de lo Penal había efectuado de las declaraciones de los recurrentes en amparo, sin respetar los principios de inmediación y contradicción».

58 «hemos trazado una delimitación, nítida al menos en el plano teórico, entre el ámbito de decisión relativo a la valoración de la prueba y fijación de los hechos probados, para el que resultará insoslayable la audiencia personal del acusado y, en su caso, de otros testigos, y aquellos pronunciamientos que quedan circunscritos a la calificación jurídica del hecho que pueden ser resueltos por el órgano ad quem sin la necesidad de celebrar vista oral».

59 «resulta contrario a un proceso con todas las garantías que un órgano judicial, conociendo a través de recurso, condene a quien había sido absuelto en la instancia o empeore su situación como consecuencia de una nueva 
Esta evolución jurisprudencial se recoge en la STC 125/2017 en la que al hilo de la resolución del recurso de amparo planteado el Tribunal realiza un recorrido por su jurisprudencia en la materia, hasta concluir con una definición del contenido del derecho a un proceso con todas las garantías en la segunda instancia penal, que quedaría vulnerado «cuando un órgano judicial conociendo en vía de recurso, condene a quien había sido absuelto en la instancia o empeore su situación a partir de una nueva valoración de pruebas personales o de una reconsideración de los hechos estimados probados, para establecer su culpabilidad, siempre que no haya celebrado una audiencia pública en que se desarrolle la necesaria actividad probatoria, con las garantías de publicidad, inmediación y contradicción que le son propias, y se dé al acusado la posibilidad de defenderse exponiendo su testimonio personal».

Con carácter más reciente la STC 146/2017 aborda la exigencia de inmediación en la valoración de pruebas personales para la determinación de la concurrencia de los elementos subjetivos del delito y el deber de audiencia de los acusados, como garantías específicas del derecho a un proceso con todas las garantías, sobre los que ya se había pronunciado en alguna ocasión el alto Tribunal ${ }^{60}$. El origen de esta resolución se encuentra en una sentencia condenatoria por delito contra la salud pública dictada en casación por el TS sobre una cuestión relativa al consumo compartido de cannabis, que por parte de la Audiencia Provincial había sido considerada irrelevante penalmente. Bien es cierto que en la sentencia el TS se hacía eco de la jurisprudencia del TEDH sobre la inmediación en el contexto de la revisión de sentencias absolutorias, aunque argumentando en esta ocasión que la Sala juzgadora se habría limitado a un aspecto puramente jurídico: «la interpretación de la norma penal y de las causas de exclusión de la antijuridicidad, sin alterar el relato contenido en los hechos probados». Para a continuación, en la segunda sentencia, incorporar una consideración respecto a la concurrencia del error como «conocimiento genérico de la conducta» ${ }^{61}$. A partir de aquí la Sala afirma el carácter vencible del error ya que los condenados «debieron cuestionarse la posible ilicitud de su conducta». Si bien fue objeto de cinco votos particulares dicha resolución, en uno de ellos se cuestiona si se excedió el Tribunal en los límites de la revisión en casación de la sentencia absolutoria $^{62}$.

Aun cuando en el recurso de amparo interpuesto contra la citada sentencia condenatoria del TS se alegaba la vulneración de la legalidad penal, tan sólo hemos de ocuparnos aquí de la vulneración de la inmediación «para la valoración de pruebas personales, al dar por probados hechos sobre los que existen dudas razonables, basándose en datos que no

fijación de los hechos probados que encuentre su origen en la reconsideración de pruebas cuya correcta y adecuada apreciación exija necesariamente que se practiquen en presencia del órgano judicial que las valora como es el caso de las declaraciones de testigos, peritos y acusados (...) sin haber celebrado una vista pública en la que se haya desarrollado todas las garantías dicha actividad probatoria».

60 »también el enjuiciamiento sobre la concurrencia de los elementos subjetivos del delito forma parte, a estos efectos de la vertiente fáctica del juicio que corresponde efectuar a los órganos judiciales debiendo distinguirse del mismo el relativo a la estricta calificación jurídica que deba asignarse a los hechos una vez acreditada su existencia» (STC 126/2012).

61 «aunque no había sido invocada, en la deliberación ...se suscitó la eventualidad de apreciar en los acusados una situación de error que pudiera atraer la aplicación del art. $14 \mathrm{CP}$.

62 «la existencia o no del dolo en la actuación» así como que «los hechos probados afirman que no queda acreditado que la asociación tuviera como finalidad pura y simplemente la distribución» a terceros de marihuana o cannabis». 
están en el relato de hechos probados, para declarar el carácter vencible del error». Por parte de nuestro alto Tribunal se atiende a la exigencia de inmediación en la valoración de las pruebas personales que, por lo que nos interesa, afecta a la inferencia que por el TS se llevó a cabo respecto de la antijuricidad de los recurrentes respecto de la calificación como vencible o invencible el error de prohibición ${ }^{63}$. De tal manera que la sentencia condenatoria del TS se fundamentó en la intención de los acusados pero deducida de los hechos probados sin ser oídos "personalmente», por lo que se llegó por la sala juzgadora en casación a desechar que el error de prohibición fuera invencible sin ser oídos los acusados en esta instancia, lo que constituyó para el TC la infracción del derecho a un proceso con todas las garantías.

$$
* * *
$$

TITLE: The right to trial with guarantees of due process in the second criminal instance

ABSTRACT: This essay focuses on the reception by the Constitutional Court of the case law of the ECtHR on the right to trial with guarantees of due process in second criminal instance, in cases where a court convicts an accused who was acquitted by the first instance.

RESUMEN: Se analiza la recepción por el Tribunal Constitucional de la jurisprudencia del TEDH sobre el derecho al proceso con todas las garantías en la segunda instancia penal cuando a través de sentencia condenatoria se revisa sentencia absolutoria en la primera instancia.

KEY WORDS: Guarantees of the right to due process, Second criminal instance, Reception of ECtHR case-law.

PALABRAS CLAVE: garantías del derecho al proceso, segunda instancia penal, recepción jurisprudencia del TEDH.

FECHA DE RECEPCIÓN: 10.05.2018 FECHA DE ACEPTACIÓN: 13.09.2018

63 «la reconsideración de los hechos estimados probados en primera instancia no se limitó a una mera discrepancia jurídica, sino a la apreciación de la posibilidad de conocer lo ilícito de su conducta, concluyendo con la alternativa error vencible de prohibición» que agravaba la absolución de la instancia, por lo que la posibilidad de los condenados de ser oídos era obligada para garantizar su defensa» (STC 146/2017). 
